\title{
Variability in the Storage and Use of Newborn Dried Bloodspots in Canada: Is it Time for National Standards?
}

\author{
DENISE AVARD, HILARY VALLANCE, CHERYL GREENBERG, CLAUDE \\ LABERGE, LINDA KHARABOYAN \& MARGO PLANT
}

\begin{abstract}
Storage and secondary use of bloodspots collected for newborn screening raises controversies because of the particularly sensitive nature of the information that can be derived from them and the lack of national standards and consistent provincial policies that can serve to guide storage facilities. This report, derived through a review of Canadian and provincial policy statements, a survey of provincial newborn screening laboratory directors and program directors, as well as through a consultative workshop, illustrates the social, ethical and legal issues regarding the storage, access and further uses of newborn bloodspots. The report indicates that there is a need for heightened transparency and clear recommendations concerning the criteria for storage, the duration of storage, and permissible secondary uses of dried bloodspots in Canada.
\end{abstract}

\section{Introduction}

Newborn screening (NBS) for serious treatable metabolic disorders has been standard-of-care in North America, Australia and Europe for over 40 years. Several tests can be done with just a few drops of blood from a baby's heel dried onto filter paper (the "blood spot card"). After testing is completed, the remaining blood spot card is usually stored. Recently, stored blood spot cards have been considered useful for a variety of other purposes. ${ }^{1,2}$ In particular, the research potential of stored newborn bloodspots and the standard practices regarding storage of dried bloodspots have become a source of debate and concern. ${ }^{3,4}$ The main purpose of NBS programs has been diagnosis and early treatment of the newborn. Thus, caution has been expressed against the risk that storage of bloodspots may compromise the important traditional public health benefits of the screening program. Considering that NBS programs are perceived as routine paediatric practice in many countries and parental consent is usually implied, the existence of such specimen banks raises issues of privacy and confidentiality. ${ }^{5}$ Regarding consent for storage and other uses, parents are being approached at a particularly vulnerable time. It is not clear whether they can distinguish the clinical purposes from consent required for storage and research purposes. ${ }^{6}$ Moreover, parental views on the topic of the retention and use of screening samples are largely unknown. ${ }^{7}$

Use of dried bloodspots for purposes unrelated to the initial collection has the potential to bring health benefits to both families and health providers. ${ }^{8}$ These blood samples are valuable for research to study: gene frequencies in the population; ${ }^{9}$ risk factors for birth defects or developmental problems; ${ }^{10}$ public health surveillance to determine for example HIV prevalence in newborns; ${ }^{11}$ and sometimes, for nonmedical purposes by helping identify disaster victims. ${ }^{12}$ In addition, because DNA is a very stable compound and can be stored for a long period of time and re-analysed at 
any time, these samples may be valuable to validate new screening tools and for clinical tests of genetic diseases. ${ }^{13}$

Nevertheless, because of the particularly sensitive nature of the information that can be derived from the newborn bloodspots, there is a need to consider the social, ethical, and legal acceptability of storage. In fact, concerns have been expressed about the potential misuse of the information by insurance companies and other third parties, including schools, governmental agencies, immigration departments and future employers. ${ }^{14}$ There are familial implications since the information may be used for health related reproductive choices. ${ }^{15,16}$ There are also concerns about the vulnerability of young persons ${ }^{17}$ and the possible psycho-social impact for the child growing up with risk information. ${ }^{18}$ Hence, careful planning and policies are required to protect stored newborn bloodspots.

A number of complex and challenging issues arise related to the justification for the storage and secondary use, possible data sharing, privacy and confidentiality, informed consent, the information to be imparted to parents, and implications for health care resources. The sensitive nature of the information introduces compelling questions. For example: When is storage justified and for what purposes? Who has access to the data derived from the bloodspots? Should explicit parental consent be sought for research using bloodspots? If parental consent is sought, how and when should this be obtained? What information should be provided to parents concerning the storage and future use of dried bloodspots? What are the costs associated with storage? Should there be a common centralised repository?

Internationally, a review of policy statements addressing storage reveals there is currently a lack of clear and consistent policies regarding the storage of newborn bloodspots. ${ }^{19}$ This lack of agreement is no different across the Canadian provinces. In Canada, universal NBS is a matter of provincial jurisdiction. As a result depending on the province, newborn bloodspots are currently stored for variable periods of time in order to permit confirmatory diagnosis, re-testing (if necessary), and quality control. The storage of dried bloodspots for these purposes is not particularly controversial and consent for such storage is usually considered to be implied (similar to the original newborn screening where consent is implied) since these uses are related to the primary purpose of the initial collection, namely screening newborns for various disorders.

Nevertheless, as mentioned above, storage raises controversies because of the particularly sensitive nature of the information that can be derived from them and because of the lack of national standards and consistent provincial policies that can serve to guide storage facilities. It is in this context that we set out to: a) determine the current practices related to the storage of newborn bloodspots in Canada; b) review and analyse the NBS policies that were in place at the time of the survey, and c) explore with a multidisciplinary group of stakeholders the social, ethical and legal dimensions of their concerns related to the storage and use of newborn bloodspots.

This paper sets out key issues identified during the survey and the consultative workshop regarding the policies and socio-ethical concerns associated with the storage of newborn bloodspots in Canada. It concludes by highlighting the potential 
and existing bioethical challenges thus laying the groundwork for the development of policies addressing storage, access and consent in Canada.

\section{Methods}

We sought information about the social, ethical and legal aspects that address the storage, access and further uses of bloodspots from the following sources: a) a review of Canadian and provincial policy statements; b) a survey of provincial NBS laboratory Directors and NBS program Directors; c) a consultative workshop.

\section{a) Policy Statements Newborn Screening}

Directors of provincial NBS laboratories and NBS programs were asked to provide written copies of their existing guidelines or documents related to NBS. We analysed four relevant documents focusing on the storage of bloodspots and checked what elements of the information on storage and research were recommended.

\section{b) Survey}

A questionnaire was developed by the principal investigators and pilot-tested with experts in the field. In February 2005, the survey was sent to the Directors of provincial newborn screening laboratories and provincial NBS committees. These individuals were usually clinicians or clinical biochemists closely involved in the management of the laboratory. Information was collected via a self-administered email survey and follow-up with phone calls to encourage a response. Items in the questionnaire focused on four key areas: written policies and program material; length and purpose of storage; uses and access of stored dried bloodspots; and consent regarding storage and use of newborn bloodspots. The questionnaire responses were analysed using SPSS and descriptive statistics are presented. The Territories were not included in the survey because the administration of their NBS programs cross provincial boundaries. For example, the western area of the Northwest Territories is covered by Alberta and the eastern area by Manitoba. In Nunavut, the western area is covered by Manitoba and the eastern area by Québec and finally, the Yukon is covered by British Columbia. ${ }^{20}$

\section{c) Consultative Workshop}

To supplement information identified in the policy review and survey and to allow more in-depth understanding of the bioethical concerns on the storage issue for Canada's NBS community, a consultative workshop was held in collaboration with the Garrod Association (www.garrod.ca). To foster a multidisciplinary dialogue about bioethical issues and to reflect different stakeholder experiences and perceptions, we brought together 40 individuals including representatives from provincial NBS laboratories, health professional associations, policy makers, consumer groups and the research community (Table I). Recruitment was carried out in collaboration with the Garrod Association of Canada organisers and the workshop was hosted at their Annual meeting in May 2005. ${ }^{21}$ 


\section{Table I. Representatives from Stakeholders Groups Invited to the Workshop}

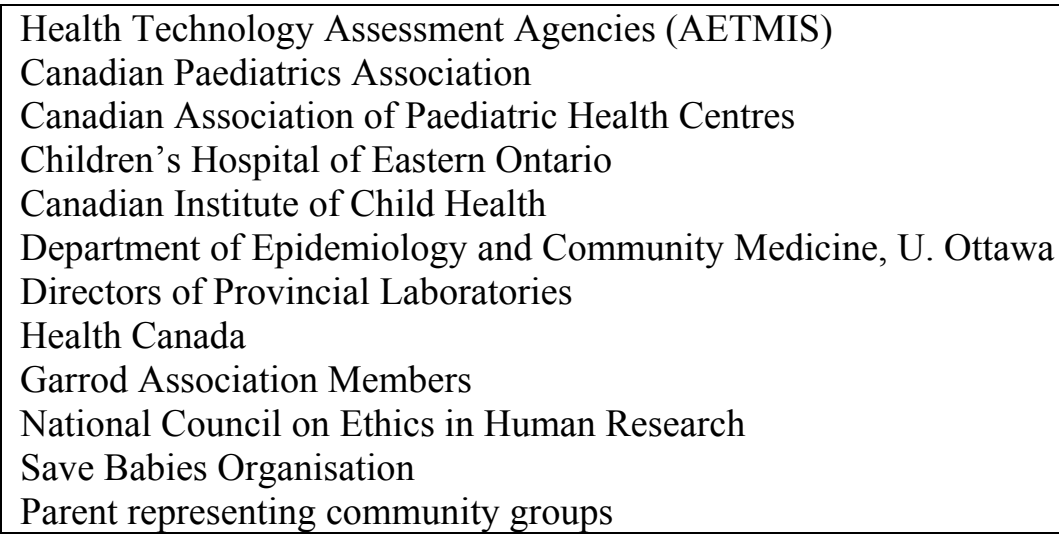

A number of provincial lab directors, who had participated in the survey, were also included in the consultative meeting. The participants were not expected to achieve consensus. Audio-recording was not possible; however, detailed notes of the workshop discussion were taken by three research assistants and principal investigators in the research team (DA, HV, CG). The notes were used to describe the ethical, social and legal views expressed when discussing newborn bloodspot storage under the three main themes of length of storage, uses of storage and consent.

\section{Ethical approval}

Ethical approval was requested and obtained from the Research Ethics Committee of the University of Montreal. Ethical approval was not required for the consultative workshop because participants would not be identified by name or associated with the issues.

\section{Results}

We draw our analysis from the review of policy statements provided by the NBS programs, the description of the survey results and from the consultative workshop.

\section{a) Written Policies Relating to Newborn Screening and Storage}

Five provinces have written policies that relate to NBS: British Columbia, Alberta, Manitoba, Québec and New Brunswick. These policies differ widely in content and detail and variably address the purpose or goals of NBS in their guidelines for the collection, transportation and storage of samples, reporting requirements, follow-up procedures, and protocols for access to the bloodspots.

Most provinces do not address the specific issue of long term storage of their newborn bloodspots. In fact, only Québec's and Manitoba's policies directly address length of storage. The Québec policies specify that samples are to be disposed of after one year unless the screening reveals an abnormality, in which case the sample is placed in a zip-lock bag and stored frozen. ${ }^{22}$ Manitoba's policy includes a specific protocol for the storage of bloodspots for Duchene muscular dystrophy screening (which are 
stored for a period of ten years); the remainder of the samples must be stored indefinitely (Protocol 3 B). ${ }^{23}$ Alberta's and New Brunswick's policies do not specifically address storage or future use of the samples. ${ }^{24}$

Only British Columbia and Manitoba provide guidelines on access/future use of the stored samples. Manitoba has a protocol for the distribution of bloodspots for approved research projects, ${ }^{25}$ which specifies that bloodspots will only be available for research once all metabolic screening tests have been performed and the recommended waiting period for retesting has elapsed (II B.2.a). ${ }^{26}$ It also specifies measures to be taken to protect patient privacy:

Blood spot samples will be assigned a different number than the CPL accession number with a Master List to be kept confidential and only stored at CPL. If a study is linked, linking to determine the identity of individual will be done by [a specified individual]. Researchers will not have access to the Master List. The follow up procedure for patients identified in linked studies must be approved by the Ethics Committee and the Manitoba Screening Committee (II B.2.b) $)^{27}$

British Columbia's policy deals with the 'Retention and Ownership of Specimens' but is not specifically conceived for newborn dried bloodspots. ${ }^{28}$ In terms of access, the policy provides that material may only be released to third parties for research, teaching or study where the approval of the Program Director or Department Head has been obtained (Policy 3.7). ${ }^{29}$ To protect patient confidentiality, no personal information may be disclosed without consent and all patient identifiers must be removed from specimens used for establishing norms or for other testing (Policy 3.6). ${ }^{30}$ Future uses of the samples are addressed in the following provision:

Body fluids which were collected for diagnostic purposes and which are intended to be discarded are considered abandoned and may be used for QA testing, determining normal values and other quality assurance activities such as method development and enhancement. However, patients should be advised at the time of their original consent for surgical/diagnostic procedures that "leftover" blood or body fluids may at some time be used for research, teaching or study. In the event that it is impossible/impractical to obtain consent for research/education use of left over specimens, the Ethics Committee approval must be given to proceed without fully informed consent (Policy 3.5). ${ }^{31}$

\section{b) Questionnaire}

For the purposes of the current paper, only the survey responses of the provincial laboratory directors or their delegates will be reported. The survey results will be described under the following topics: i) length and purpose of residual bloodspots storage, ii) use of and access to residual bloodspots, and iii) consent for storage.

i) Duration and purpose of storage

The survey results demonstrate that there is currently no consistency between provinces as to length of storage of newborn bloodspots. Indeed, duration of storage varies significantly from province to province, ranging from one to more 
than 21 years. Québec, Newfoundland and Nova Scotia store bloodspots for one to five years; British Columbia and Alberta store them for five to ten years; whereas Saskatchewan, Manitoba, Ontario and New Brunswick store them for more than 21 years (Table II). The vast majority of provinces store the samples using personal identifiers. But, Manitoba and Québec have provided additional privacy protection by single or double coding the samples, respectively (Table II).

Table II. Duration and type storage of dried spots samples across Provinces

\begin{tabular}{|l|l|l|}
\hline Province & Duration of storage (years) & Type of storage \\
\hline British Columbia & $5-10 \mathrm{yrs}$ & Identified \\
\hline Alberta & $5-10 \mathrm{yrs}$ & Identified \\
\hline Saskatchewan & $>21 \mathrm{yrs}$ & Identified \\
\hline Manitoba & $>21 \mathrm{yrs}$ & Single-coded \\
\hline Ontario & $12-21 \mathrm{yrs}$ & Identified \\
\hline Québec & $1 \mathrm{yr}$ & Double-coded \\
\hline Newfoundland & $1-5 \mathrm{yrs}$ & Identified \\
\hline Prince Edward Island & $1-5 \mathrm{yrs}$ & Identified \\
\hline Nova Scotia & $5 \mathrm{yrs}$ & Identified \\
\hline New Brunswick & $>21 \mathrm{yrs}$ & N/A \\
\hline
\end{tabular}

Table III illustrates the most frequently cited purposes for storing residual bloodspots, with the most common reasons being: quality assurance, retesting to confirm results, and post-mortem diagnosis. Less commonly, bloodspots are stored for the purpose of developing and validating new tests, epidemiological research, and special family studies. Public health research, other medical research, and future DNA testing were infrequently cited as reasons for storage. Forensic studies were not identified by any province as a reason for storage.

Table III. Reasons for storage of residual bloodspots

\begin{tabular}{|l|c|}
\hline Purpose & Frequency \\
\hline Retesting to confirm test results & 8 \\
\hline Quality assurance & 8 \\
\hline Post-mortem diagnosis & 6 \\
\hline Develop \& validate tests & 5 \\
\hline Epidemiological research & 4 \\
\hline Special family studies & 4 \\
\hline Public health research & 3 \\
\hline Other medical research & 3 \\
\hline Future DNA testing & 2 \\
\hline Forensic studies & 0 \\
\hline
\end{tabular}

The responses to the question "Are there any costs associated with bloodspot storage?" revealed a range of estimates and uncertainties. In some provinces, the cost factor was unknown; others described the cost as 'minimal' or 'quite 
significant.' One respondent suggested there is a need to take into consideration storage space, monitoring of environmental conditions and security levels, privacy and quality assurance standards when determining cost.

\section{ii) Uses of /access to dried bloodspots}

As mentioned in the policy review, British Columbia and Manitoba are the only provinces where written policies exist for the use of, or access to, residual specimens. Nevertheless, processes were reported to exist for the release of dried bloodspots from other provincial laboratories for various purposes (Table IV). Of note, the provincial laboratory had formal processes in place for the release for research purposes, medico-legal uses, and forensic purposes in five provinces, whereas three provinces have a process for release for quality assurance. Procedures were also reported to exist for the use of newborn bloodspots within the provincial laboratory to validate a method or establish levels of confidence (five provinces), to evaluate new technologies (four provinces), and for new DNA/RNA analysis (one province).

When asked for what purposes bloodspots have been requested, respondents reported that bloodspots had been requested for post mortem diagnosis in 6 provinces, for epidemiological research in four provinces, for future DNA diagnostic testing in three provinces, for other medical research in two provinces, for public health research in one, and for special family studies in one. No provinces report requests for release of dried bloodspots for forensic or legal research (such as victim identification or non-paternity testing). (Table III)

Table IV. Does the provincial laboratory have a process for the release of dried bloodspots?

\begin{tabular}{|l|c|c|c|c|c|c|c|c|c|c|}
\hline Uses & BC & ALTA & SASK & MAN & ON & QC & NFLD & PEI & NS & NB \\
\hline Research & Y & Y & N & Y & Y & Y & N & Y & Y & N \\
\hline Medico-Legal & Y & Y & N & N & Y & Y & N & Y & Y & N \\
\hline Forensic & Y & Y & N & N & Y & Y & N & Y & Y & N \\
\hline Quality Assurance & Y & Y & N & N & Y & Y & N & N & Y & N \\
\hline
\end{tabular}

iii) Consent for storage and use

None of the provinces require written consent for the storage of dried bloodspots. Consent to storage is generally implicit, but parents are nevertheless free to opt out of storage in all provinces other than Manitoba. It is worth noting, however, that only in British Columbia and Nova Scotia are parents given written information that the child's screening sample will in fact be stored (Table V).

Only three of the provincial laboratories require parental written consent prior to use of newborn bloodspots for secondary purposes (Québec, Ontario and Saskatchewan). In no province are donors asked to provide renewed consent once they have reached the age of majority (Ontario was unclear on this). It must be noted, however, that only four provinces currently retain bloodspots for long 
enough that the donor would in fact reach the age of majority during the storage period.

Table V. Consent and storage policies by province

\begin{tabular}{|l|c|c|c|c|c|c|c|c|c|c|}
\hline Questions & BC & ALTA & SAS & MAN & ON & QC & NFL & PEI & NS & NB \\
\hline $\begin{array}{l}\text { Are the hospitals required } \\
\text { to obtain written consent } \\
\text { for the storage of dried } \\
\text { bloodspots? }\end{array}$ & $\mathrm{N}$ & $\mathrm{N}$ & $\mathrm{N}$ & $\mathrm{N}$ & $\mathrm{N}$ & $\mathrm{N}$ & $\mathrm{N}$ & $\mathrm{N}$ & $\mathrm{N}$ & $\mathrm{N}$ \\
\hline $\begin{array}{l}\text { Are parents given any } \\
\text { written information that } \\
\text { the child's screening } \\
\text { sample will be stored? }\end{array}$ & $\mathrm{N}$ & $\mathrm{N}$ & $\mathrm{N} / \mathrm{A}$ & $\mathrm{N} / \mathrm{A}$ & $\mathrm{N} / \mathrm{A}$ & $\mathrm{N} / \mathrm{A}$ & $\mathrm{N} / \mathrm{A}$ & $\mathrm{N}$ & $\mathrm{N}$ & $\mathrm{N} / \mathrm{A}$ \\
\hline $\begin{array}{l}\text { Does the laboratory } \\
\text { require written parental } \\
\text { consent prior to use of } \\
\text { residual specimens? }\end{array}$ & $\mathrm{N}$ & $\mathrm{N}$ & $\mathrm{Y}$ & $\mathrm{N}$ & $\mathrm{Y}$ & $\mathrm{Y}$ & $\mathrm{N}$ & $\mathrm{N}$ & $\mathrm{N}$ & $\mathrm{N}$ \\
\hline $\begin{array}{l}\text { Is explicit written consent } \\
\text { a requirement for uses of } \\
\text { newborn bloodspots for } \\
\text { others purposes? }\end{array}$ & $\mathrm{N}$ & $\mathrm{N}$ & $\mathrm{Y}$ & $\mathrm{N}$ & $\mathrm{Y}$ & $\mathrm{Y}$ & $\mathrm{N} / \mathrm{A}$ & $\mathrm{N}$ & $\mathrm{N}$ & $\mathrm{N} / \mathrm{A}$ \\
\hline $\begin{array}{l}\text { Does the NBS program } \\
\text { have any written policies } \\
\text { with regards to bloodspots } \\
\text { storage? }\end{array}$ & $\mathrm{N}$ & $\mathrm{N}$ & $\mathrm{N} / \mathrm{A}$ & $\mathrm{N}$ & $\mathrm{N} / \mathrm{A}$ & $\mathrm{N}$ & $\mathrm{N} / \mathrm{A}$ & $\mathrm{N}$ & $\mathrm{N}$ & $\mathrm{NA}$ \\
\hline $\begin{array}{l}\text { Does the provincial } \\
\text { laboratory have a written } \\
\text { policy for the use of } \\
\text { residual specimens? }\end{array}$ & $\mathrm{Y}$ & $\mathrm{N}$ & $\mathrm{N}$ & $\mathrm{Y}$ & $\mathrm{N}$ & $\mathrm{N}$ & $\mathrm{N}$ & $\mathrm{Y}$ & $\mathrm{Y}$ & $\mathrm{N}$ \\
\hline $\begin{array}{l}\text { Can parents request access } \\
\text { or destruction of stored } \\
\text { samples? }\end{array}$ & $\mathrm{Y}$ & $\mathrm{Y}$ & $\mathrm{Y}$ & $\mathrm{N} / \mathrm{A}$ & $\mathrm{N} / \mathrm{A}$ & $\mathrm{Y}$ & $\mathrm{N} / \mathrm{A}$ & $\mathrm{Y}$ & $\mathrm{Y}$ & $\mathrm{Y}$ \\
\hline
\end{tabular}

\section{c) Consultative Workshop}

In order to address the concerns about the storage of newborn bloodspots all participants were asked to consider three central issues: i) the appropriate length of storage; ii) uses and access; iii) the nature of the consent required for secondary uses.

i) Duration and purposes of storage

Much of the discussion in the group was centered on short vs. long term storage issues. Participants explored the rationale underlying short as opposed to long term storage. It seems that the traditional benchmark of five years is based on the assumption that most metabolic diseases will manifest within this time. In Québec, samples are routinely stored for only one to two years because this is thought to provide sufficient time for confirmatory tests in normal cases; abnormal samples are stored for a longer period. Another reason to limit storage time is that the quality of the sample deteriorates over time, especially if not stored under ideal conditions. Finally, the fact that consent is presumed was cited as a factor supporting a shorter 
storage time. Specific rationale for storing samples for extended periods of time were not voiced, but, presumably, the length of storage will be directly related to the anticipated future uses of the samples. It was noted that the length of storage and the types of uses envisioned will determine to a great extent the nature of the consent required.

As storage duration increases, the costs of storage will also increase. It seems that the costs of adequate storage can be quite significant. Storage costs will therefore likely be factored into policy making around the appropriate length of storage for bloodspots. One solution proposed to eliminate provincial disparities with respect to storage was the creation of a central repository: blood samples could be stored by the provinces for the initial five-year period and subsequently sent to a central repository for use in research.

\section{ii) Uses of/access to dried bloodspots}

Overall, the respondents discussed the potential value of NBS bloodspots for research. However, there was less general support for other purposes such as DNA diagnostic testing, post-mortem analysis, special family studies, forensic studies, etc. It was agreed that there may be appropriate and inappropriate secondary uses of newborn dried bloodspots although there was diversity on where to draw the line and how to proceed. All participants concurred, nonetheless, that if the samples are to be used for secondary purposes, these uses should not interfere in any way with the primary purposes of NBS. It was also common ground that secondary uses should be congruent with existing ethical guidelines.

The discussion focussed primarily on the secondary use of dried bloodspots for research purposes. There was a general, if not unanimous sentiment that use for research may be permissible in certain circumstances. The respondents felt that as long as identifiers have been removed in accordance with the Tri-Council Policy Guidelines $^{32}$ and the American Academy of Pediatrics ${ }^{33}$ amongst others, then researchers should be allowed to use the bloodspots. The Tri-Council Policy, for example, provides that if the data within a database are anonymous/non-identifying, then researchers should be allowed to use that database (section 3.3). Because research projects generally require research ethics board (REB) approval, it was recognised that research protocols will automatically be subject to review and inappropriate uses will presumably be denied. Some felt that both the Tri-Council Policy statement and the review by REBs provide sufficient safeguards.

However, workshop participants were also concerned about the proficiency of the REBs to determine appropriate research uses, especially where the proposed research is complex. It was noted that REBs' interpretations and standards vary from board to board and decisions therefore appear arbitrary. Participants suggested, as a safeguard, the creation of a council with the stem cell research model in mind, where CIHR's Stem Cell Oversight Committee (SCOC) must approve research projects involving human stem cells before granting funding to an institution, prior to and in addition to REB approval. ${ }^{34}$ Under this model, complex research projects would first have to be approved by this national panel of experts before being submitted to the local REB. 
Concern about the use of newborn dried bloodspots for forensic purposes was also discussed. While at least one participant felt that storage and use of samples for future forensic purposes was justifiable from a public policy perspective, the majority believed that such use would violate our country's tradition of individual liberties. The use of newborn bloodspots for forensic purposes was said to be equivalent to fingerprinting everyone in the country. Most agreed that we should be cautious about taking that route because of the potential misuse.

\section{iii) Consent for storage and use}

The discussion centred on the more contentious issue of whether consent should be required for secondary uses of stored samples. There was no consensus as to whether informed consent, be it of a general or specific nature, should be obtained before newborn dried bloodspots may be used in research. The issue of whether informed consent is required can vary depending on the type of research and the degree of anonymity. Many participants felt that when samples are anonymized and submitted to an ethics board for review, research can be conducted without explicit consent. It was recognised that anonymization may entail ethical problems where the research detects something that is of relevance to the health of the individual, since the origin of the sample cannot be traced and so the patient cannot be informed.

Given the very small number of parents who opt out of screening programs, some questioned the necessity of obtaining consent for research purposes. However, it was suggested that an evaluation of refusal rates could be carried out. If only a negligible proportion of parents are found to refuse, then the consent requirement could be dispensed with. This type of reasoning has been applied in Manitoba where written consent was originally required for use of bloodspots in research, but because nobody ever refused, the REB allowed the written consent to be dropped. ${ }^{35}$

Another concern was raised with respect to obtaining explicit informed consent for secondary uses. It was felt that were explicit informed consent to become a requirement due to the use of the samples for various secondary purposes, participation rates in screening programs on the whole may be negatively affected. If this were the case, then the primary purpose of the screening would be impaired. This could be seen as a justification for not requiring explicit consent and relying instead on anonymization and ethics board approval. It was noted, however, that the elimination of a consent requirement on the basis of a sample of public opinion may not be defensible in this era of increasing recognition of individual autonomy and privacy rights, and more so, in light of the CIHR Guidelines for Human Pluripotent Stem Cell Research, where parental consent is a requirement in any research involving human stem cells derived from a newborn's umbilical cord.

A different issue that was discussed is parental wishes to be informed about storage. Regardless of whether consent is implied or explicit, there was consensus that parents should be informed about the screening program in general. Participants also indicated the need for information about possible future use of the samples, and about the intended duration of storage. Information on NBS is generally provided to parents in written form as part of a prenatal package and/or at the time of birth. In some provinces, such as Québec, this information includes the length of storage. 
However, the participants questioned whether written information was actually read and understood by parents. The Québec experience relating to additional screening of urine indicates that brochures can be effective in conveying this sort of information. Information on this additional screening program is provided to parents in brochure form and parents are required to take the initiative to send the urine samples in themselves. 89\% of parents in Québec sent back their child's urine sample; this participation rate may be seen as an indication that the materials were in fact read and understood. $^{36}$

\section{Discussion}

This review provides descriptive information about the provision of newborn screening program policy for bloodspot storage and uses of stored samples by surveying Directors of NBS programs and consulting multiple stakeholders. In light of the growing interest in newborn bloodspots and considering the potential health benefits that could emerge from research using bloodspots, proactive solutions should be entertained to ensure proper protection and choice. ${ }^{37}$

As revealed by the survey and consultation workshop, there is a lack of uniformity in provincial approaches to storage of dried bloodspots, uses and access, and the amount of information given to parents about storage. Most provinces do not have written policies on the specific issue of long-term storage of newborn bloodspots. However, some provincial NBS programs (3 out of 10) had policies regarding storage. About half of the provincial programs indicated they had some formal measures in place for the release of bloodspots for research, medico-legal and forensic purposes.

Our findings are consistent with other studies demonstrating variability in practices. $^{38,39}$ One of the changes that has taken place on the international scene has been the development of recommendations that provide a national framework of principles and procedures to address the retention of newborn bloodspots and their secondary use. ${ }^{40,41,42,43}$ The variations in provincial policies testify to the need for common standards in Canada. The development of such policies requires a consultative process. Traditionally, NBS programs were decided administratively by the health department with little or no input from the public. ${ }^{44}$ However, today, openness, collaboration and partnership have become the norm, and it is accepted that a range of stakeholders should participate. ${ }^{45}$ Stakeholders in the NBS community include the directors of laboratories, policy makers, clinicians, patients, public representatives and other related communities that have a stake in defining NBS policies. While there is a need to develop written policies for retention, usage and release of dried bloodspots, such policies should be developed and endorsed in consultation with these stakeholders in a manner that fosters multidisciplinary and pluralistic dialogue ${ }^{46}$ and introduces a broad social consensus. ${ }^{47}$ Moreover while the cost estimate of storing NBS was brought up by one participant and is an important issue we did not set up our research question to address or discuss this topic in greater detail. There are many components that need to be integrated into this cost estimate including storage, quality control and transportation variables. 
Overall while no specific recommendations were generated by the working group meeting at the Garrod Association annual meeting, the workshop provided the groundwork for further discussions and policy development in this area.

Reasons for storage include non-controversial purposes such as for laboratory audit, the development of new tests or for confirming a diagnosis. However, these reasons represent only one component of the uses. Samples could also be used for research purposes. Overall, there was considerable support for, and recognition of the notion that dried blood samples are a valuable resource for medical research, and that their use should be carefully managed with appropriate safeguards. The survey data regarding access and further uses of cards indicated that the primary uses of the stored bloodspots were for the screening program and that other uses of NBS cards rarely occurred. Similarly, during the consultation workshop it was recognised that although newborn bloodspots constitute valuable research tools, the storing of bloodspots should not hinder the primary screening purpose of the NBS program. While storage of NBS was seen as a factor that argues against the justification for epidemiological research, it has been shown that NBS are especially useful for research that will provide considerable health benefits for children. ${ }^{48,49}$

The secondary use of NBS cards also raises ethical challenges regarding the protection of privacy and confidentiality. In fact, the survey revealed that the cards were occasionally stored with their identifiers and at other times were anonymized. The participants in the consultative workshop indicated that research can be conducted as long as identifiers are removed and REB approvals are consistent with the guidelines set by the Tri-Council's report. ${ }^{50}$ Moreover it would appear from a survey $^{51}$ in Australia, that the public is supportive, considering over $85 \%$ of the cohort of new mothers believed that anonymised samples should be made available for research. However, the question of anonymisation raises important ethical concerns since the research findings may detect relevant health information for the infant, yet because of the de-identification there is no way of tracing the individual. To improve the usefulness of the archived materials, more and more double-coding has emerged as a tool which promotes confidentiality and ongoing research. ${ }^{52}$

While informed consent is considered relevant to the storage and use of dried bloodspots, and while parents have a right to be informed of this occurrence, ${ }^{53}$ our survey and workshop could not pinpoint whether explicit consent to future use of bloodspots should be obtained, and if so, whether that should take place at the time of collection or at the time they are requested for research purposes. An overview of the importance of informed consent for research with biological samples reveals disagreement on the type of consent that is needed. ${ }^{54}$ It has recently been suggested that if at the time of collection, bloodspots are intended to be used in a research project, that written consent be sought at the time of collection; if no particular research is foreseen, written consent would need to be obtained in the absence of anonymisation. ${ }^{55}$ For some types of research (ie, longitudinal or disease oriented), a system of coding or double-coding combined with parental consent may be more appropriate. Yet, overall there appears to be no consensus as to whether an explicit informed consent should be required for secondary uses. However, anonymisation and ethics board approval without explicit consent may be sufficient for research purposes. ${ }^{56}$ Concerns raised by the workshop participants over the variability in 
approaches by different REBs are also reflected in the literature. ${ }^{57}$ However since there are many potential benefits to be gained from using NBS for epidemiological research, it can be argued that research without explicit consent is worthwhile if proper mechanisms are in place to protect individual information from improper use. It is important to note that a new trend is emerging whereby individual ethics of privacy and immediate personal benefit are traded for the benefit of others including future others. ${ }^{58}$

Closely associated with consent is the need for better information about the consent process and of the informational material provided to parents to obtain their permission. ${ }^{59}$ When should parents be informed about newborn screening? What type of information should be provided? Because the information might matter to the child, how and when should relevant information be conveyed to children? It has been proposed that prior to birth, and whether or not explicit consent for screening is required, information should be made available to parents regarding the following: purpose, duration and method of storage, potential uses of residual samples, possibility or impossibility of being re-contacted, possibility or impossibility of receiving research results, ownership of samples, access to residual bloodspots and right to refuse storage or to withdraw. ${ }^{60}$ Challenges that may impede understanding include language barriers and variation in educational levels. The points of view of parents also need to be further researched. Finally, concerns about costs associated with providing security to prevent unauthorised use, disclosure, loss or other misuse need to be evaluated.

A potential limitation of this study is the small sample size. We sought information from laboratory directors and a sample of representative stakeholders regarding the social, ethical and legal aspects of the retention storage, access and further uses of NBS bloodspots. While the consultation workshop is an obvious attempt to obtain a broad-based representation, there is a need for broader consultation with respondents from other areas of Canada. To ensure a broader representation, we suggest similar consultative workshops in each province and territory as they develop their policies regarding the storage of newborn bloodspots.

Another obvious limitation is that a survey with closed-ended answers limits our understanding of the existing context of the policy process. As indicated, there are processes in place for the release of dried bloodspots from provincial laboratories for various purposes. Notably, five provincial laboratories had formal processes in place for the release of bloodspots for research, medico-legal and forensic purposes.

Interviews with the key respondents in each province would provide real-life personal situations and enhance our understanding of the link between these processes and the policies.

\section{Conclusion}

In this study, we have identified a lack of written policies and procedures in several Provincial newborn screening programs across Canada in relation to the storage and potential future use of stored bloodspots. In accordance with standard laboratory practice, policies and procedures need to be explicit and transparent. Considering the sensitive nature of the information that can be derived from bloodspots, there is a need 
for heightened transparency and clear policies concerning the criteria and length of storage, as well as permissible secondary uses of dried bloodspots.

Presently, there is no national newborn screening organisation to address national standards in Canada. Achieving a national consensus will require a commitment from both provincial and federal stakeholders. Consequently, it would be valuable to have an established forum for the development of comprehensive policies that would include the issues described above. The Garrod association, which is a professional body that promotes the prevention, diagnosis and management of hereditary metabolic disease, has been instrumental in the development of national guidelines. Existing national professional bodies with an interest in metabolic medicine and newborn screening, in conjunction with other stakeholders, would be well-suited to tackle issues related to newborn screening at the national level.

Lessons learned from this experience testify that:

- the variations in policies across the country are clearly a challenge;

- the workshop serves as a launching pad for both further discussion and a national policy development in this area;

- despite the broad interests and multiple disciplines of participants, there is a remarkable uniformity in terms of commitment to the development of newborn bloodspot collection and storage policies across Canada;

- the development of policies in this area requires a rational and systematic approach.

\section{Acknowledgements}

The authors thank the following people for their assistance with the completion of the project: Beth Potter, Karine Sénécal, the directors of newborn programs, the Garrod Association and the Canadian Institutes of Health Research for funding this project.

\footnotetext{
${ }^{1}$ B. Almond. Genetic profiling of newborns: ethical and social issues. Nat. Rev. Genet. 2006; 7: 67-71.

${ }^{2}$ L. Kharaboyan, D. Avard, B.M. Knoppers. Storing newborn blood spots: modern controversies. J. Law Med. Ethics 2004; 32: 741-748.

${ }^{3}$ C. Laberge, L. Kharaboyan, D. Avard. Newborn screening, banking, and consent. GenEdit 2004; 2: 115.

${ }^{4}$ B.L. Therrell. U.S. newborn screening policy dilemmas for the twenty-first century. Mol. Genet. Metab. 2001; 74: 64-74.

${ }^{5}$ J.E. McEwen and P.R. Reilly. Stored Guthrie cards as DNA "banks". Am. J. Hum. Genet. 1994; 55 : 196-200.

${ }^{6}$ UK Newborn Screening Programme Centre. 2005. Newborn Blood Spot Screening in the UK Policies and Standards. London: 1-38

${ }^{7}$ A. Davey, D. French, H. Dawkins, P. O'Leary. New mothers' awareness of newborn screening, and their attitudes to the retention and use of screening samples for research purposes. Genomics, Society and Policy 2005; 1: 41-51.

${ }^{8}$ Almond, op. cit., note 1 .

${ }^{9}$ M.Z. Pelias. Newborn Screening - New Dilemmas Informed Consent and the Use of Archived Tissues Samples. Corn Conference on Genetic Services. 2004.
} 
${ }^{10}$ American Academy of Pediatrics (AAP). Serving the family from birth to the medical home. Newborn screening: a blueprint for the future - a call for a national agenda on state newborn screening programs. Pediatrics 2000; 106: 389-427.

${ }^{11}$ Ibid.

12 J.G. Loeber et al. 2001. Legality of Long Term Storage of Newborn Filter Paper Cards.. Washington, Association of Public Health Laboratories. Proceedings of the Newborn Screening and Genetic Symposium.

${ }^{13}$ AAP, op. cit., note 10.

${ }^{14}$ N.J. Kerruish et al. Newborn screening: new developments, new dilemmas. J.Med.Ethics 2005; 31: 393-398.

${ }^{15}$ AAP, op. cit., note 10 .

${ }^{16}$ M.A. Lloyd-Puryear and I. Forsman. Newborn screening and genetic testing. J. Obstet. Gynecol. Neonatal Nurs. 2002; 31(2): 200-207.

${ }^{17}$ T.M. Burke, R. Abramovitch and S. Zlotkin. Children's understanding of the risks and benefits associated with research. J. Med. Ethics 2005; 31: 715-720.

${ }^{18}$ D. Avard and B.M. Knoppers. Screening and Children: policy issues for the new millenium. Can. J. Policy Res. 2001; 2(3): 46-55.

${ }^{19}$ Kharaboyan et al., op. cit. note 2 .

${ }^{20}$ W.B. Hanley. Newborn screening in Canada - Are we out of step? Paediatrics and Child Health 2005; 10: 203-207.

${ }^{21}$ Garrod Symposium. Garrod Association. 2005. Ottawa.

${ }^{22}$ Réseau de Médecine Génétique du Québec. Conservation des Échantillons sur Papier Buvard. 2005. Québec, Ministère des Affaires Sociales; Université Laval, McGill, Montréal, Sherbrooke.

${ }^{23}$ Manitoba Perinatal Screening Committee. Neonatal Screening Specimen Collection Guidelines. 2003. Manitoba.

${ }^{24}$ Health Surveillance Alberta Health. Alberta Newborn Metabolic Screening Standards/Guidelines. 112. 2000. Alberta Health and Wellness.

${ }^{25}$ P. Van Caeseele. Guidelines for the Handling of Blood Spot Cards at CPL. Protocol II. 2004. Manitoba, Manitoba Cadham Provincial Laboratory.

${ }^{26}$ Ibid.

${ }^{27}$ Ibid

${ }^{28}$ Children's \& Women's Health Centre of British Columbia, Department of Pathology and Laboratory Medicine. Standard Operating Procedures- Ref No. 1-06, Retention and Ownership of Specimens. Revised March 2004, Vancouver British Columbia.

${ }^{29}$ Ibid.

${ }^{30}$ Ibid.

31 Ibid.

${ }^{32}$ Medical Research Council of Canada, Natural Sciences and Engineering Research Council of Canada, and Social Sciences and Humanities Research Council of Canada. Tri-Council Policy Statement - Ethical Conduct for Research Involving Humans. Canadian Institute of Health Research. 1998.

${ }^{33}$ American Academy of Pediatrics. Serving the Family From Birth to the Medical Home. A Report From the Newborn Screening Task Force Convened in Washington DC, May 10-11, 1999. Pediatrics 2000; 106: 383-427.

${ }^{34}$ Canadian Institutes of Health Research. Guidelines for Human Pluripotent Stem Cell Research: Policy Details. 2005. Ottawa, Canadian Institutes of Health Research.

${ }^{35}$ C.R. Greenberg et al. Outcome of the first 3-years of a DNA based neonatal screening program for glutaric acidemia type 1 in Manitoba and northwestern Ontario, Canada. Mol. Genet. Metab 2002; 75 : $70-78$.

${ }^{36}$ Ministère de la Santé et des Services Sociaux du Québec. L'organisation des services de génétique au Québec - plan d'action 2005-2008. 2005. Québec, Ministère de la Santé et des Services Sociaux du Québec.

${ }^{37}$ Kharaboyan et al., op. cit. note 2.

${ }^{38}$ B.L. Therrell et al. Guidelines for the Retention, Storage, and Use of Residual Dried Blood Spot Samples after Newborn Screening Analysis: Statement of the Council of Regional Networks for Genetic Services. Biochem. Mol. Med. 1996; 57: 116-124. 
${ }^{39}$ Advisory Group on Human Gene Patents and Genetic Testing. Consultation document. Principles and guidelines for newborn screening - a uniform approach to newborn screening based on bloodspots for Australia. 2005. Australia, The Australian Health Minister's Advisory Council (AHMAC).

${ }^{40}$ UK Newborn Screening Programme Centre, op. cit., note 6.

${ }^{41}$ AAP, op. cit., note 10 .

${ }^{42}$ Advisory Group on Human Gene Patents and Genetic Testing, op.cit. note 39.

${ }^{43}$ B. Norgaard-Pederson. 1997. Use of stored samples from the Danish PKU register. In Human DNA: Law and Policy, International and Comparative Perspectives. B.M. Knoppers, ed. Amsterdam, Kluwer Law International: 303-311.

${ }^{44}$ N.A. Holtzman. What role for public health in genetics and vice versa? Community Genet. 2006; 9 : 8-20.

${ }^{45}$ E.H. Hiller, G. Landenburger and M.R. Natowicz. Public participation in medical policy-making and the status of consumer autonomy: the example of newborn-screening programs in the United States [see comments]. Am. J. Public Health 1997; 87: 1280-1288.

${ }^{46}$ UNESCO. Universal Declaration on Bioethics and Human Rights. 2005. Geneva, UNESCO.

${ }^{47}$ S.D. Gross, C.A. Boyle, A.Kenneson, M.J. Khoury and B.S. Wilfond. From public health emergency to public health service: the implications of evolving criteria for newborn screening panels. Pediatrics 2006; 117: 923-929.

${ }^{48}$ C. Hankins. Research on Surveillance: Anonymous Seroprevalence Studies-Ethical and Epidemiological Considerations in Public Health Planning. Genetic Screening from Newborns to DNA Typing. Amsterdam: Excerpta Medica; 1990. 87-94.

${ }^{49}$ B.K. Van Naarden, M. Yeargin-Allsopp, D. Schendel, P. Fernhoff. Long-term developmental outcomes of children identified through a newborn screening program with a metabolic or endocrine disorder: apopulation-based approach. J. Pediatrics 2003: 143(2): 236-242.

${ }^{50}$ Medical Research Council of Canada, Natural Sciences and Engineering Research Council of Canada, and Social Sciences and Humanities Research Council of Canada, op. cit., note 32.

${ }^{51}$ Davey et al, op. cit. note 7 .

${ }^{52}$ B.M. Knoppers. Consent revisited: points to consider. Health Law Review 2005;13: 33-36.

${ }^{53}$ Laberge et al., op. cit. note 3.

${ }^{54} \mathrm{D}$. Wendler. One-time general consent for research on biological samples. BMJ 2006; 332: 544-547.

${ }_{56}^{55}$ Laberge et al., op. cit. note 3 .

${ }^{56}$ Davey et al, op. cit. note 7.

${ }^{57}$ H. Silverman, S. Chandros Hull and J. Sugarman. Variability among institutional review boards' decisions within the context of a multicenter trial. Crit. Care Med. 2001; 29: 235-241.

${ }^{58}$ Knoppers, op.cit. note 52.

${ }^{59}$ K.E. Fant, S.J. Clark and A.R. Kemper. Completeness and complexity of information available to parents from newborn-screening programs. Pediatrics 2005; 115: 1268-1272.

${ }^{60}$ Laberge et al, op. cit. note 3 . 